\title{
Investigation of sustainable development potential for Ulubey Aquifer System, Turkey
}

\author{
UNSAL BURCU \& YAZICIGIL HASAN \\ Department of Geological Engineering, Middle East Technical University, 06800, Cankaya, Ankara, Turkey \\ burcunsal@gmail.com
}

\begin{abstract}
This study investigates sustainable development potential for Ulubey aquifer system which serves as an important water supply for Usak province (Turkey). In recent years, growing population, accelerating industrial activities and decreasing rainfall, as well as contamination of the surface water resources, made groundwater indispensable to meet the freshwater demands of Usak province. Therefore, a sustainable groundwater development plan has to be set up by determining the sustainable yield of the system, which is the aim of this study. To achieve this goal, a mathematical groundwater flow model is constructed in order to test the alternative development scenarios. Results show that the system preserves equilibrium conditions under present stresses. The future effects of possible increases in stresses are also simulated and based on the dynamic responses of the system to changing stresses; sustainable yield and sustainable pumping rate of the aquifer are determined and compared with the safe yield of the system.
\end{abstract}

Key words Ulubey aquifer; numerical modelling; simulation; sustainability

\section{INTRODUCTION}

Groundwater supplied from a regional aquifer system, namely Ulubey aquifer, is the main freshwater source to meet domestic, industrial and agricultural demands of Usak province, located in the inner parts of the Aegean Region in Turkey (Fig. 1). In recent years, growing population, accelerating industrial activities and decreasing rainfall, as well as contamination of the surface water resources, significantly increased groundwater consumption. Growing demand reveals the concern about the management of groundwater so that it is not depleted while the increasing demand is satisfied.

In addressing the issue of groundwater management, there are several approaches such as safe yield, sustainable yield and sustainable pumping rate; each of them defines the limits for groundwater extraction aiming to preserve it for future generations (Romano and Preziosi 2010). The term "safe yield" was first described as the amount of groundwater that can "regularly and permanently" be extracted without dangerously depleting the reserve (Lee 1915). Since then, this concept has evolved and its conception is explained as the attainment and maintenance of a longterm balance between the amount of groundwater withdrawn annually and the annual amount of recharge. Sophocleous criticizes this approach on accepting the amount of pumping that is equal to the natural replenishment as safe, ignoring the discharge from the system (Sophocleous 1997). Bredehoeft (2002) also criticizes the approach relating the amount of discharge solely to the recharge of the system and suggests that the amount of discharge that can be sustainably captured from the system depends on the dynamic response of the aquifer system to the development. On the other hand, another concept, sustainable pumping rate, is defined as the maximum exploitation that can be maintained indefinitely without mining an aquifer. Sustainable pumping rate narrows down the concept and does not address the general sustainability issues. Another important difference introduced by this term is that recharge can be very important to consider when assessing sustainability, but is not necessary to estimate sustainable pumping rates (Devlin and Sophocleous 2005). Moreover, an estimate of the sustainable pumping rate is necessary but is not sufficient to assess the conditions for sustainability (Romano and Preziosi 2010). Although commonly criticized, the safe yield approach paved the way for the further fruitful discussions, which resulted in a shift from the safe yield to sustainable yield. Sustainable yield of an aquifer, which should definitely be less than recharge or the safe yield, is defined as the amount of groundwater that can be extracted given that both quantity and quality of streams, springs, wetlands, and groundwater-dependent ecosystems are sustained at the same time (Sophocleous 2000). A sustainable development plan is based on the dynamic response of the aquifer system to changing stresses, which can be determined 
by mathematical groundwater models (Bredehoeft 2002). Hence, this study, using a groundwater flow model, aims to determine the groundwater development potential of the Ulubey aquifer system that would satisfy the growing demand on freshwater while ensuring the sustainability of all the other hydrologic components such as baseflows and spring discharges.

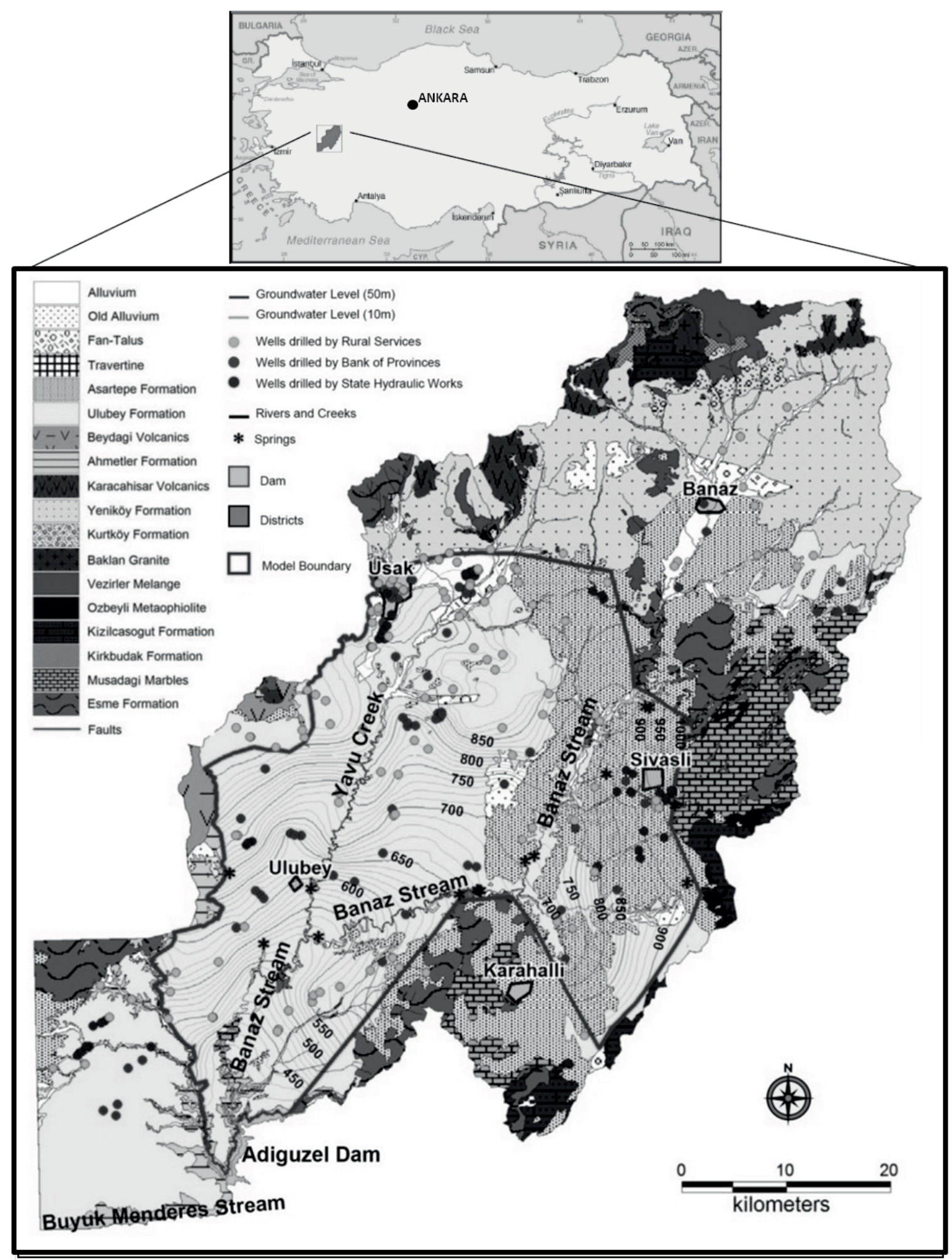

Fig.1 Location map of the study area. 


\section{BACKGROUND INFORMATION FOR THE STUDY AREA}

The study area is located in the neighbourhood of Usak province and covers an area of $3972 \mathrm{~km}^{2}$, enclosing the whole Banaz River Basin (Fig. 1). Banaz River drains an area of $3475 \mathrm{~km}^{2}$, which corresponds to $87 \%$ of the study area. Elevation of the study area decreases from $2200 \mathrm{~m}$ in the north to $300 \mathrm{~m}$ in the south (Yazicigil et al. 2008). A continental type of climate is dominant in the area, where the weather is hot and dry in the summer, but cold and rainy/snowy in the winter. The annual precipitation is $460 \mathrm{~mm}$ for dry years and $516 \mathrm{~mm}$ for average rainfall years.

The major surface water resources within the study area are Banaz River, which has an average discharge rate of $5.39 \mathrm{~m} / \mathrm{s}$; and its major tributary Yavu Creek. Banaz River joins the Buyuk Menderes River in the south of the study area (Fig. 1). Moreover, in the basin $43.17 \mathrm{hm}^{3}$ of groundwater is drained by the springs annually.

All lithological units are classified into major hydrogeological groups according to their groundwater bearing capabilities. Within the study area, from a regional point of view, marbles, the Ulubey Formation, Asartepe Formation and alluvium are classified as good aquifers. However, due to the lack of detailed information about the marbles that would be required in the mathematical model, marbles are not simulated. Instead, lateral flow to and from the marbles is introduced into the model domain. Consequently, a model of two layers, the upper one simulating the Asartepe Formation and alluvium, and the lower one simulating the Ulubey Formation, is designed.

More than 250 wells have been drilled in the study area by governmental agencies since 1960 for different purposes including exploration, irrigation, domestic and industrial uses. The fact that more than $97 \%$ of these wells were drilled after 1990, indicates a significant increase in demand for groundwater. Irrigational, domestic and industrial groundwater consumptions are separately determined for each hydrogeological unit within the study area. Moreover, cooperatives exist that are currently operating and planned for irrigation by the State Hydraulic Works in two phases in order to meet the future irrigational water demand. In total, an area of 2200 hectare is planned to be irrigated with the groundwater that will be extracted from the wells of these cooperatives in the following years.

In order to determine the areal distribution and to create a groundwater level map, groundwater levels measured in April 2007 are taken as a basis, as they represent the latest dry period with full coverage of the study area. According to these measurements, groundwater level of the Ulubey aquifer is around $900 \mathrm{~m}$ in the north and $1000 \mathrm{~m}$ in the east, then decreases gradually towards the southwest where it is equal to $410 \mathrm{~m}$ (Fig. 1). The maximum saturated thickness of $250-300 \mathrm{~m}$ is noted along Yavu Creek between Usak and Ulubey districts and it is around 100-150 $\mathrm{m}$ in the inner parts of the basin; depth to groundwater ranges between $50 \mathrm{~m}$ and $150 \mathrm{~m}$. Temporal variation of groundwater levels have been observed by the State Hydraulic Works since 1965 by monitoring wells. As a result of a detailed study on groundwater level hydrographs and meteorological data, it is observed that except very minor influences of the dry periods, groundwater levels of the Ulubey aquifer are not influenced by the present pumping stresses. This implies that an equilibrium condition is achieved with these pumping rates.

\section{GROUNDWATER FLOW MODEL AND DEVELOPMENT SCENARIOS}

A model of two layers, the upper one simulating the Asartepe Formation and alluvium, and the lower one simulating Ulubey Formation, is designed and lateral flow from marbles to the system is considered in the simulation (Unsal 2008). A numerical groundwater flow model is developed by means of the MODFLOW code (Harbaugh et al. 2000). The model domain covers an area of $1700 \mathrm{~km}^{2}$. A uniform grid size of $500 \mathrm{~m}$ by $500 \mathrm{~m}$ is applied at first, and then at critical locations where higher accuracy is required the grid size is refined to $100 \mathrm{~m}$ by $100 \mathrm{~m}$.

The model is calibrated under steady state conditions, until a good match between groundwater levels observed in the field and calculated by the model is achieved. During calibration, spring discharges and baseflow rates, are also considered (Fig. 2). At the end, a calibrated model having a Root Mean Square Error (RMS) percentage of 5.1 is achieved. 
Furthermore, a sensitivity analysis is also performed and its results indicated that the model is very sensitive to both increase and decrease in hydraulic conductivity and increase in recharge, whereas the model is not sensitive to changes in anisotropy as much as to the changes in other parameters.
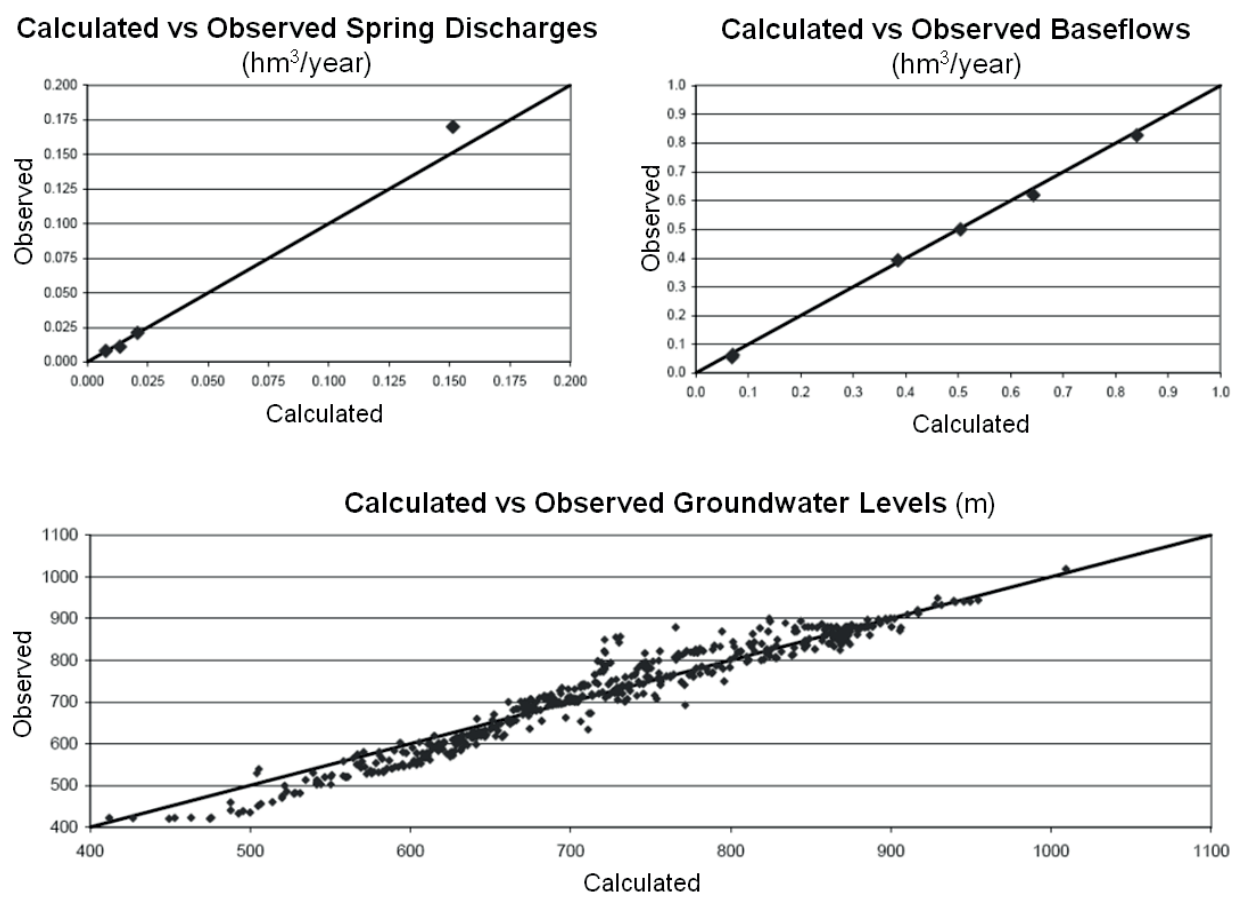

Fig. 2 Calibration plots for groundwater levels, baseflow and spring discharges.

The calibrated groundwater flow model is further used as a tool to set up and test alternative development scenarios under transient conditions. The effects of four scenarios are tested for a planning period of 20 years, consisting of monthly time steps. First of these scenarios, Scenario A is based on the assumption that demand for groundwater will not change for the next 20 years. Scenario B simulates the effects of pumping for irrigation from cooperatives planned by the State Hydraulic Works in the first phase to meet the present additional demand, in addition to the base pumping schedule of April 2007. An area of 780 hectares is predicted to be irrigated with 4.62 $\mathrm{hm}^{3} /$ year of groundwater extracted at eight cooperatives within the model domain. Scenario C simulates the effects of additional pumping to meet the growing demand in case of a potential population increase in Usak city, in addition to the pumping schedule of Scenario B. In this alternative, a continuous increase in population creates an increasing gap between present supply and future demand, which is predicted to reach $373 \mathrm{~L} / \mathrm{s}$ at the end of 20 years. For this purpose, a total of 20 wells are introduced in the model, in a stepwise manner, such that five wells are additionally activated in each period of 5 years. Scenario D simulates the effects of increased pumping from the cooperatives, which are proposed by the State Hydraulic Works for the second phase, to meet the future demand on freshwater for irrigation. An additional area of about 1200 hectares is planned to be irrigated with an additional $6.8 \mathrm{hm}^{3} /$ year of groundwater.

\section{RESULTS AND DISCUSSION}

Within the scope of this study, groundwater budget and dynamic responses of the system to the changing stresses simulated with the mathematical model are utilized in order to construct sustainable development scenarios based on these. Data produced by running the groundwater flow model under different pumping schedules changing according to the related scenario, are checked by groundwater level hydrographs at critical locations within the basin. Results showed that Scenarios A and B produced no significant decline in groundwater levels and groundwater reserves 
for the average recharge conditions. In fact, a slight rise in groundwater levels is expected under Scenario A, as the initial conditions of the model represented a dry year with low water levels. The average regional drawdown under Scenario $\mathrm{C}$ is calculated as $2.3 \mathrm{~m}$ for the whole model domain and drawdown in the locality of the proposed well field for this scenario reaches $20 \mathrm{~m}$, which corresponds to less than $10 \%$ of the saturated thickness at this locality. The average regional drawdown under Scenario D is calculated as $3.0 \mathrm{~m}$ for the whole model domain and maximum additional drawdown simulated among the well fields proposed for this scenario reaches $10.8 \mathrm{~m}$ at the end of the irrigation period in summer and decreases to $7.0 \mathrm{~m}$ at the end of the recharge period in spring.

Moreover, the average groundwater budget of the Ulubey aquifer system is calculated for each development scenario at the end of the 20 years planning period (Table 1). Water budget of Scenario $\mathrm{D}$ indicates that this scenario corresponds to the maximum amount of groundwater pumping and the average reserve change at the end of the planning period is calculated as a decrease of $7.8 \mathrm{hm}^{3}$. However, when responses of each component of the system are examined separately, it can be observed that there are insignificant changes and the amount of annual decrease in reserve for Scenario D, is also insignificant compared to the total budget of the system.

Table 1 Groundwater budget of the Ulubey aquifer system.

\begin{tabular}{|c|c|c|c|c|c|}
\hline & Scenario & $\mathrm{A}$ & $\mathrm{B}$ & $\mathrm{C}$ & $\mathrm{D}$ \\
\hline \multirow{6}{*}{ 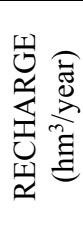 } & Precipitation & 64.2 & 64.2 & 64.3 & 64.3 \\
\hline & Subsurface Inflow & 62.3 & 62.5 & 62.5 & 62.5 \\
\hline & Surface Inflow & 10.1 & 10.1 & 10.1 & 10.1 \\
\hline & Banaz Stream & 0.4 & 0.5 & 0.5 & 0.6 \\
\hline & Asartepe Form. and Alluvium & 53.5 & 53.8 & 54.6 & 54.0 \\
\hline & Total & 190.6 & 191.1 & 191.9 & 191.5 \\
\hline \multirow{8}{*}{ 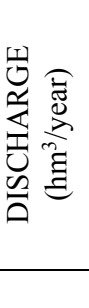 } & Wells & 6.4 & 11.0 & 16.6 & 21.0 \\
\hline & Subsurface Outflow & 54.1 & 53.7 & 53.1 & 53.0 \\
\hline & Springs & 5.3 & 5.3 & 5.3 & 5.2 \\
\hline & Banaz Stream & 103.3 & 101.8 & 100.8 & 99.3 \\
\hline & Adiguzel Dam & 11.0 & 11.0 & 11.0 & 11.0 \\
\hline & Asartepe Form. and Alluvium & 10.0 & 10.0 & 10.1 & 9.8 \\
\hline & Total & 190.0 & 192.7 & 196.9 & 199.3 \\
\hline & Change in Reserve & 0.6 & -1.6 & -4.9 & -7.8 \\
\hline
\end{tabular}

In order to compare the results obtained from different scenarios, trade-off curves are produced by plotting average regional drawdown calculated at the last dry season and average annual decrease in the groundwater reserve against the pumping rates of each scenario (Fig. 3). Both trade-off curves show that there are two quasi-equilibrium states, one at lower pumping rates and another at higher levels of pumping and a transition stage in between. These two quasi-equilibrium states are significant and should be investigated in detail to determine the dynamic responses and to assess the sustainability of the system. The graph of the average regional drawdown versus maximum pumping rate for each scenario, suggests that a pumping rate of $35000 \mathrm{~m}^{3} /$ day does not affect the regional groundwater levels. In addition to this, it could be observed that the same amount of pumping produces no change in the groundwater reserves. Based on these outcomes, sustainable yield of the Ulubey aquifer is suggested as $35000 \mathrm{~m}^{3} /$ day $\left(12.8 \mathrm{hm}^{3} /\right.$ year). Furthermore, the second quasiequilibrium state corresponding to the higher pumping levels of around $130000 \mathrm{~m}^{3} /$ day $(47.5$ $\mathrm{hm}^{3} /$ year), producing an acceptable average regional drawdown of $3 \mathrm{~m}$ and average annual decrease in reserve of almost $8 \mathrm{hm}^{3}$, is suggested as the sustainable pumping rate of the system. However, the safe yield of the system, according to its traditional definition, equals the natural replenishment from the precipitation that is $176000 \mathrm{~m}^{3} /$ day $\left(64.2 \mathrm{hm}^{3} /\right.$ year $)$. However, the so-called "safe yield" of the system does not take other components of the hydrologic system, such as the discharge to the surface waters, into account, which is a very important component of the Ulubey aquifer system. 


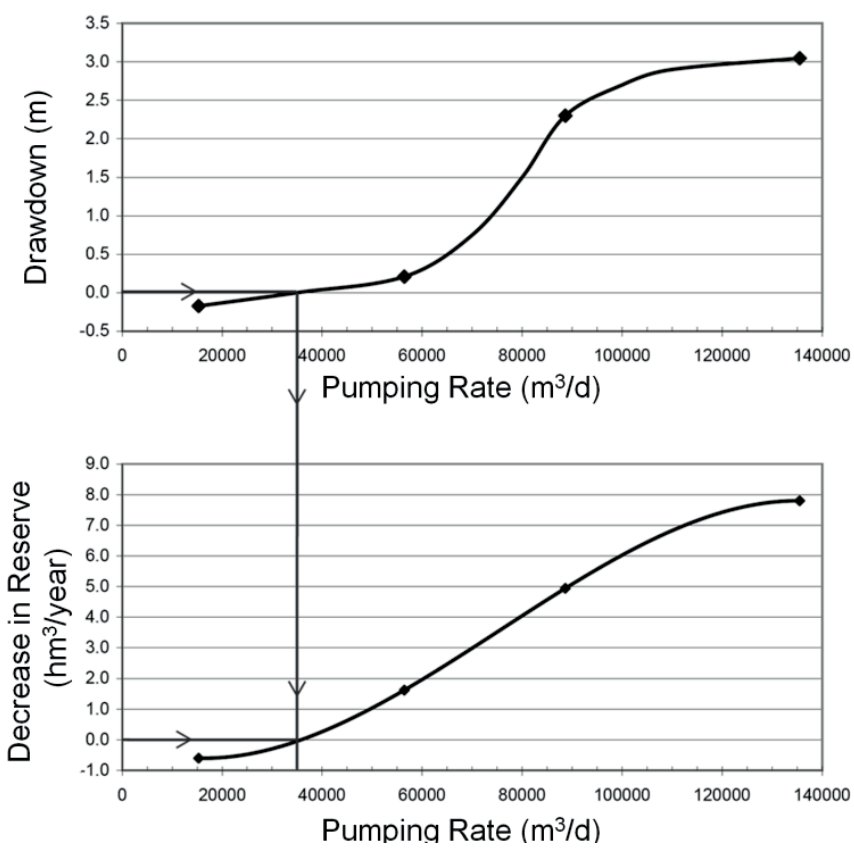

Fig. 3 Trade-off curves.

\section{CONCLUSION}

Results of this study show that the Ulubey aquifer system preserves the equilibrium conditions under present stresses. However, it is obvious that the present pumping rates will not be able to satisfy the growing demand on groundwater for irrigational and domestic uses. Hence, four alternative groundwater development plans are set up and effects of cooperative irrigations planned by the State Hydraulic Works and of possible increase in groundwater demand due to population increase are simulated with these scenarios. Based on the simulation results, two quasi-equilibrium states for the system, one at lower pumping rates corresponding to the sustainable yield and the other at higher levels of pumping corresponding to the sustainable pumping rate, are determined. In contrast, the safe yield of the system based on its traditional definition is almost $30 \%$ greater than the sustainable pumping rate. Thus, pumping at safe yield is expected to decrease groundwater reserves, baseflow and discharges of springs significantly. It should be noted that sustaining the increasing demand on groundwater is a critical issue that should be satisfied. Hence, decision makers have to choose an appropriate pumping policy considering the social and economic factors together with the discussed hydrologic responses of the system.

\section{REFERENCES}

Bredehoeft, J. D. (2002) The Water Budget Myth revisited: why hydrogeologists model. Ground Water 40(4), 340-345.

Devlin, J. F. and Sophocleous, M. (2005) The persistence of the water budget myth and its relationship to sustainability. Hydrogeology Journal 13(35), 549-554.

Harbaugh, A. W. et al. (2000) MODFLOW-2000, the U.S. Geological Survey modular ground-water model: user guide to modularization concepts and the groundwater flow process. U.S. Geological Survey, Open-File Report, 00-92.

Lee, C. H. (1915) The determination of safe yield of underground reservoirs of the closed basin type. Transactions, American Society of Civil Engineers 78, 148-251.

Unsal, B. (2008) Modeling and development of a groundwater management plan for Ulubey Aquifer System, Usak - Turkey, MSc Thesis, Middle East Technical University, Ankara, Turkey.

Romano, E. and Preziosi, E. (2010) The sustainable pumping rate concept: Lessons from a case study in Central Italy. Ground Water 48(2), 217-226.

Sophocleous, M. (1997) Managing water resources systems: Why "safe yield" is not sustainable. Ground Water 35(4), 561.

Sophocleous, M. (2000) From safe yield to sustainable development of water resources: the Kansas experience. Journal of Hydrology 235, 27-43.

Yazicigil, H., et al. (2008) Hydrogeological investigation report and groundwater management plan for Ulubey aquifer, Usak. Middle East Technical University, Ankara, Turkey, Project no: 07-03-09-2-00-04 \& 07-03-09-2-00-07. 